\title{
Injury control in developing nations: what can we learn from industrialized countries?
}

\author{
Samuel N Forjuoh
}

In spite of the enormous differences between industralized countries and developing countries regarding their economics, politics, education, and health priorities, as well as their culture, developing countries can learn health care management from the experiences of industrialized countries. Injury control is no exception. After all, why spend time reinventing the wheel? Injury prevention is the study, identification, and implementation of strategies to prevent or reduce the transfer of energy to the human body or to ensure the supply of such essentials as heat or oxygen to the body. The various forms of energy that may injure the human body include mechanical energy, as in a motor vehicle collision or during a fall, thermal energy, as in a scald burn, electrical energy, as in an electrocution, or chemical energy, as in some forms of poisoning. The human body may also be denied heat during hypothermia, and oxygen during drowning or near drowning.

The same public health approach used to successfully eliminate smallpox in both industrialized countries and developing countries has already been applied to injury control in the industrialized world with some success. Much of what we currently know about injury control has been made possible by the pioneering works of several individuals, including Hugh de Haven, Edward Press, John Gordon, James Gibson, and William Haddon Jr - all of whom worked in industrialized countries, ${ }^{1-5} \mathrm{Hugh}$ de Haven paved the way for our understanding of the importance of injury thresholds in the biomechanical energy exchanges, ${ }^{1}$ while Press was the first to propose the epidemiologic approach to injury control. ${ }^{2}$ Together Gordon and Gibson defined the agent of injury, ${ }^{34}$ and Haddon is credited with the development of the structured framework for modern injury prevention. ${ }^{56}$ All these scientific contributions have led to the current understanding of the model of injury causation and the methods for intervention in industrialized countries. Although no injury type has yet been eradicated, the incidence of many has been reduced drastically. For example, a $50 \%$ reduction was observed for childhood falls from windows after an intervention program in New York City. ${ }^{7}$ With the present trend, near elimination of many injury types is attainable in the industrialized world.

Developing countries are now hanging between the stages of epidemiologic polarization and protracted epidemiologic transition. This means that they have the onerous task of tackling the problem of injuries on top of the longstanding problems of infections, malnutrition, and other serious emerging health problems like HIV/AIDS, diabetes, and hypertension. Thus, in spite of the recent recognition of the importance of injury control by several developing countries, other competing health problems do not permit many developing countries to have the time, take the time, and spend the time and resources to adequately deal with this other major public health problem. The problem is further compounded by the fact that injuries are still viewed in many developing countries as random, haphazard events, or even 'as acts of God'.

However, in any way one looks at it, the injury problems from unintentional causes seen in many developing countries are an exact mirror image of those seen in industrialized countries. The exchanges of energy that cause injuries - be they mechanical, thermal, electrical, or chemical - are the same in industrialized countries as in developing countries. Injuries from motor vehicle collision, falls, burns, and poisonings comprise the bulk of unintentional injuries in developing countries ${ }^{8}$ just as in industrialized countries. ${ }^{9}$ Intentional injuries, however, vary slightly due to the prevalence of specific consumer products that are utilized as vectors of the injury causation. For example, firearm related injuries are much more prevalent in the United States partly due to the fact that half of all homes contain a firearm. ${ }^{10}$

The science of injury control has been expanded to encompass the totality of health including prevention, promotion, timely treatment, and rehabilitation. For example, injury prevention and promotion campaigns include education of the public about behaviors on how to avoid certain injuries. Public encouragement on the use of safety belts in automobiles and installation and proper placement of smoke detectors on all habitable floors of residential dwellings are but two examples of the myriad of injury prevention drives.

The combination of poor resources, lack of personnel, and high illiteracy rates in developing countries dictates that they learn injury control from industralized countries. This learning process should involve the epidemiology, mechanisms, and the patterns of injury in different segments of the population. For instance, the epidemiology of childhood injuries has been found to be characterized by a different set of factors due to the fact that the 
child is not a miniature adult. The relatively large head of the child in relation to the small body size, coupled with developmental differences, increases the vulnerability of the child's head to injury, for example a higher incidence of axonal shearing injuries than in adults.

Other aspects of injury control worth learning by developing countries from industrialized countries include:

- The scientific basis for injury control research, which is likely to be updated from time to time

- Peer identification of all persons involved in injury control research

- Public involvement in the injury control process

- Use of multisectoral and intersectoral cooperative efforts for injury control

- The formation of regional task forces on injury control to facilitate and advocate

- The standardization of injury data and methods to permit comparisons

- Inclusion of the science of injury control in health curricula, for example medical schools

- Increased use of the Internet

- Establishment of centers for injury research, control, and policy

- The organization of regional conferences on injury prevention and control.

Nevertheless, I agree that it is very dangerous for developing countries to copy blindly and adopt all the countermeasures for injuries developed largely in industrialized countries. For example, it would be ridiculous for developing countries to try to import expensive intensive care unit technologies when many emergency departments in these countries barely have enough supplies or staffing. On the other hand, copying technologies like the use of helmets by motorcyclists, which has been proven effective in industrialized countries, is the right thing to do. In fact, motorcycle helmet use is being utilized effectively in many developing Asian countries and saves many dear lives. We can also learn much from the failures in injury control from the industrialized world which, I believe, are as valuable as the many success stories.

1 De Haven H. Mechanical analysis of survival in falls from heights of fifty to one hundred and fifty feet. War Med 1942; 2: 586-96.

2 Press E. Epidemiologic approach to accident prevention. $\mathrm{Am}$ f Public Health 1948; 38: 1442-5.

3 Gordon JE. The epidemiology of accidents. Am 7 Public Health 1949; 39: 504-15.

4 Gibson JJ. The contribution of experimental psychology to the formulation of the problem of safety: a brief for basic research. Reprinted from: Behavioral approaches to accident research. New York: New York Association for the Aid of Crippled Children, 1961: 77-89.

5 Haddon W Jr. On the escape of tigers: an ecologic note. $A m \mathcal{F}$ Public Health 1970; 60: 2229-34.

6 Haddon W Jr. Advances in the epidemiology of injuries as a basis for public policy. Public Health Rep 1980; 95: 411-21.

7 Spiegel CN, Lindaman FC. Children can't fly: a program to prevent childhood morbidity and mortality from window falls. Am $\mathcal{F}$ Public Health 1977; 67: 1143-7.

8 Smith GS, Barss P. Unintentional injuries in developing countries: the epidemiology of a neglected problem. Epidemiol Rev 1991; 13: 228-66.

9 Baker SP, O'Neill B, Ginburgh MJ, Li G. The injury fact book. New York: Oxford University Press, 1992

10 US Department of Justice, Bureau of Justice Statistics. Crime victimization in the United States. Washington, DC: US Department of Justice, 1993.
Health Economics and Financing Programme, Health Policy Unit, London School of Hygiene and Tropical Medicine, Keppel Street, London WC1E 7HT, UK

\title{
Injury control in developing countries: context more than content is crucial
}

\author{
Anthony B Zwi
}

Injury prevention and control has, in recent decades, made considerable strides in a number of industrialised countries. Forjuoh draws attention to many of these and recommends that lessons from the successful application of injury interventions be applied in low and middle income countries.

$\mathrm{He}$ is right: there is much experience that can benefit others; resources are scarce and should not be wasted. But, while there is no doubt that countries can learn from each other, considerable caution should be exercised in assuming the applicability and relevance of injury control policies in vastly different contexts.

Consider the content of injury control policy, the context in which it is formulated and implemented, the processes through which this is done, and the actors involved. In seeking to generalise lessons from one setting to another, the content of injury control interventions is least likely to be contentious: establishing what works and applying these interventions where possible is seen as the priority. But even here, there may be difficulties in transposing effective interventions between settings. Take the example of traffic safety. Dinesh Mohan, one of the leading proponents of appropriate injury control policy in low and middle income countries, argues that the extremely rapid growth of vehicle stock in South East Asia, the mix between different types of transport (motorised and unmotorised, including animal drawn, and 